\title{
Frontotemporal Dementia in Southeast Asia: A Comparative Study
}

\author{
Yee-Leng Tan ${ }^{\mathrm{a}} \quad \mathrm{Amanda}^{\mathrm{Ng}}{ }^{\mathrm{a}}$ Nagaendran Kandiaha, ${ }^{\mathrm{a}} \mathrm{b}$ \\ ${ }^{a}$ Department of Neurology, National Neuroscience Institute, and ${ }^{\text {b }}$ Duke-NUS Graduate \\ Medical School, Singapore
}

\section{Key Words}

Dementia • Frontotemporal dementia - Magnetic resonance imaging • Neuropsychology • Behavior

\begin{abstract}
Background: The clinical profile of frontotemporal dementia (FTD) in Southeast Asia is not known. We characterized and compared the demographic and clinical characteristics of FTD patients in Southeast Asia with North Asian and Western patients. Methods: The study included Southeast Asian FTD patients presenting to a tertiary neurology institute. Behavioral variant (bv-FTD) and language variant (Iv-FTD) subtypes of FTD were diagnosed based on the LundManchester criteria. The patients were characterized according to demographics, clinical, neuroimaging and longitudinal profiles. Results: Twenty-five bv-FTD and 19 lv-FTD patients were identified, with a female predominance ratio of 2:1 and a mean age of 56 years. The mean MMSE score was 16.2 , and $88.4 \%$ of patients had memory symptoms. Over $5.1 \pm 2.4$ years of followup, $60 \%$ of bv-FTD and $36.8 \%$ of Iv-FTD patients developed a second FTD syndrome. bv-FTD was the predominant type of FTD among Southeast Asians. Conclusion: FTD represents an important cause of young-onset dementia in Southeast Asia. Greater awareness of FTD is required to ensure early diagnosis and management.




\section{Introduction}

Frontotemporal dementia (FTD) is one of the leading causes of young-onset dementia in individuals $<65$ years of age [1]. This neurodegenerative condition was first clinically defined by the Lund and Manchester groups [2] in 1994, and subsequently revised by Neary et al. [cited in 3]. The latest diagnostic recommendations for the behavioral and language variants of FTD were recently published by Rascovsky et al. [4] and Gorno-Tempini et al. [5].

Currently, the term 'FTD' refers to the clinical syndromes of behavioral variant FTD (bv-FTD) and language variant FTD (lv-FTD). The lv-FTD is further subdivided into progressive non-fluent aphasia (PNFA) and semantic dementia (SD). Ultimately, behavioral and language symptoms often overlap in later stages of the disease [6]. There is also an overlap of FTD with motor disorders, namely the corticobasal syndrome, progressive supranuclear palsy, and motor neuron disease [7].

There is a paucity of clinical studies on FTD in Asia. The National Neuroscience Institute in Singapore is a tertiary center which receives referrals for cognitive impairment and dementia from both local and regional sources. A significant proportion of referred patients (27.7\%) have young-onset dementia. FTD is the third leading cause of young-onset dementia after Alzheimer's disease (AD) and vascular dementia in our clinical database.

In this paper, we aim to characterize the profile of FTD in a Southeast Asian population. The demographics, cognitive symptoms, and longitudinal follow-up profiles are described and compared with published literature from North Asia and Western countries.

\section{Methods}

\section{Sample and Data Collection}

A retrospective review of a prospective clinical database was performed. All FTD patients attending the dementia clinic between August 2008 and April 2012 were studied. Sources of referrals included general neurology clinics, psychiatry clinics, geriatric clinics, primary healthcare services, as well as general practitioners and specialists from both local and regional sources.

A chart review was performed to obtain data from clinical interviews and neurological examinations. Data from neuropsychological assessments including the Mini Mental State Examination (MMSE), Montreal Cognitive Assessment (MOCA), and frontal assessment battery (FAB) scales were obtained [8-12].

Neuroimaging [magnetic resonance imaging (MRI)/computed tomography (CT) of the brain] findings were also analyzed. The cerebral atrophy was rated visually by two independent assessors blinded to the subjects' clinical profile. Frontal lobe atrophy (FLA) was quantified using the global cortical atrophy scale (range $0-3$ ), medial temporal atrophy (MTA) via the Scheltens scale (range $0-4$ ), and white matter changes via the Fazekas scale (range 0-3) [13-15]. Fluorodeoxyglucose positron emission tomography (FDG-PET) imaging data wherever available were also collected.

\section{FTD Diagnosis}

FTD was diagnosed using the Lund-Manchester criteria [2]. FTD patients were divided into bv-FTD and lv-FTD subtypes. Subjects were excluded from the study if they had alternative diagnoses. These included chronic primary psychiatric disorders such as schizophrenia and personality disorders, neuroimaging with confounding diagnoses (normal pressure hydrocephalus, multi-territorial infarcts, space-occupying lesions), and central nervous system infections including neurosyphilis and HIV infection. 
Table 1. Baseline demographics of FTD subjects

\begin{tabular}{lcc}
\hline & bv-FTD $(\mathrm{n}=25)$ & lv-FTD $(\mathrm{n}=19)$ \\
\hline Referral source, $\mathrm{n}(\%)$ & & \\
$\quad$ Primary healthcare & $13(52)$ & $11(58)$ \\
Neurology clinics & $5(20)$ & $2(11)$ \\
Geriatric clinics & $2(8)$ & $5(26)$ \\
Psychiatry clinics & $5(20)$ & $1(5)$ \\
Male gender, $\mathrm{n}(\%)$ & $9(36)$ & $5(26)$ \\
Mean duration of education \pm SD, years & $10.6 \pm 5.7$ & $10.9 \pm 4.9$ \\
Race, $\mathrm{n}(\%)$ & & \\
Chinese & $18(72)$ & $15(79)$ \\
Malay & $1(4)$ & $2(11)$ \\
Indian & $3(12)$ & $2(11)$ \\
Others & $3(12)$ & 0 \\
Mean age at diagnosis \pm SD, years & $58.5 \pm 8.4$ & $59.2 \pm 7.5$ \\
Mean duration of symptoms before diagnosis of & & \\
FTD \pm SD, months & $41.4 \pm 31.6$ & $24.2 \pm 14.3$ \\
Initial diagnosis at referring source, $\mathrm{n}(\%)$ & $3(12)$ & \\
FTD & $14(56)$ & $11(58)$ \\
Psychiatric disorder & $5(20)$ & $4(21)$ \\
AD & 0 & $2(11)$ \\
Vascular dementia & $3(12)$ & $1(5)$ \\
Encephalopathy & $4 / 25(16)$ & $2 / 19(11)$ \\
Family history of dementia, n/total $n(\%)$ & & \\
\hline
\end{tabular}

\section{Standard Patient Consent}

Informed consent was obtained from participants or their legal guardians for their data to be included in the database as per institutional ethics board requirements.

\section{Results}

\section{Demographics}

A total of 44 FTD patients were identified during the study period. Their baseline demographics are shown in table 1 . Twenty-four (54.5\%) of the referrals to our dementia clinic were from primary healthcare clinics, with the rest coming from general neurology clinics (15.9\%), geriatric memory clinics (15.9\%), and psychiatry clinics (13.6\%).

Other than patients from Singapore, there were also FTD patients from Malaysia, Indonesia, Philippines, and Vietnam. The mean age at diagnosis of FTD was 58.9 years, with a 2:1 female predominance. Thirty-three subjects (75\%) were Chinese, $3(6.8 \%)$ were Malays, 5 were Indians (11.4\%), and 3 were of other races (6.8\%). Six subjects (13.6\%) had a positive family history of dementia in a first-degree relative. There were $25 \mathrm{bv}$-FTD and $19 \mathrm{lv}$-FTD subjects. Within the lv-FTD group, 17 had PNFA and 2 had SD. Amongst the FTD subjects, 3 had FTD and corticobasal syndrome, and 1 had FTD and motor neuron disease.

The bv-FTD subjects suffered the longest duration of symptoms (41.4 months) before the diagnosis of FTD was made. In contrast, the lv-FTD group had significantly shorter symptom duration prior to diagnosis (24.2 months). The delay to diagnosis in bv-FTD subjects was likely caused by a high percentage of subjects (56.0\%) being initially misdiagnosed as having a primary psychiatric disorder due to their behavioral and personality changes. 
Table 2. Symptomatology of FTD subjects

\begin{tabular}{|c|c|c|}
\hline & bv-FTD $(n=25)$ & lv-FTD $(n=19)$ \\
\hline Executive impairment, n (\%) & $25(100)$ & $17(89)$ \\
\hline Visuospatial disturbance, $\mathrm{n}(\%)$ & $13(52)$ & $9(47)$ \\
\hline Memory complaint, n (\%) & $23(92)$ & $16(84)$ \\
\hline Loss of insight, $\mathrm{n}(\%)$ & $24(96)$ & $12(63)$ \\
\hline \multicolumn{3}{|l|}{ Behavioral symptoms, n (\%) } \\
\hline Loss of social awareness & $24(96)$ & $9(47)$ \\
\hline Loss of personal awareness & $23(92)$ & $7(37)$ \\
\hline Disinhibition & $16(64)$ & $7(37)$ \\
\hline Apathy & $11(44)$ & $8(42)$ \\
\hline Stereotypic behavior & $5(20)$ & $2(11)$ \\
\hline Mental rigidity & $22(88)$ & $5(26)$ \\
\hline Depression & $12(48)$ & $8(42)$ \\
\hline Aggression & $13(52)$ & $1(5)$ \\
\hline Delusion/hallucination & $9(36)$ & $1(5)$ \\
\hline Hyperorality & $8(32)$ & $0(0)$ \\
\hline Hyperreligiosity & $2(8)$ & $1(5)$ \\
\hline \multicolumn{3}{|l|}{ Language symptoms, n (\%) } \\
\hline Word finding difficulty & $10(40)$ & $17(89)$ \\
\hline Paraphasia & $7(28)$ & $6(32)$ \\
\hline Echolalia & $2(8)$ & $2(11)$ \\
\hline Impaired comprehension & $9(36)$ & $5(26)$ \\
\hline Loss of semantic knowledge & $8(32)$ & $4(21)$ \\
\hline Mutism & $8(32)$ & $8(42)$ \\
\hline Apraxia, n (\%) & $9(35)$ & $12(63)$ \\
\hline Agnosia, n (\%) & $10(40)$ & $5(26)$ \\
\hline Akinesia, n (\%) & $4(16)$ & $4(21)$ \\
\hline Rigidity, n (\%) & $6(24)$ & $7(37)$ \\
\hline Pyramidal signs, n (\%) & $2(8)$ & $1(5)$ \\
\hline
\end{tabular}

\section{Clinical Symptoms}

The symptoms of FTD subjects at the time of first assessment at the dementia clinic can be found in table 2, detailing the range of symptoms manifested over the follow-up period. The mean duration of follow-up from time of FTD diagnosis was 2.4 years.

Executive dysfunction (95.4\%) and memory symptoms (88.6\%) were significant features in all our FTD subjects. By the time of presentation, all previously employed subjects were no longer working or had opted for early retirement. Memory complaints, when present, were mostly related to poor working memory. Visuospatial dysfunction was a prominent symptom with $52 \%$ of patients having gotten lost in unfamiliar places. However, some preserved their abilities to take public transportation.

All 25 bv-FTD subjects demonstrated core features of personality change and early decline in social and interpersonal conduct with loss of insight into their condition. Those who became disinhibited (64.0\%) usually showed unaccustomed public nudity or public incontinence, conducted acts of public theft, or became over-friendly or aggressive to strangers and family members. Eight patients (32.0\%) developed food cravings, and 9 $(36.0 \%)$ developed persecutory delusions. Mental rigidity was strongly featured, with 22 patients $(88 \%)$ demonstrating perseveration of lone activities, for example, cooking the same food or travelling to the same destination daily. A subset also showed obsessive traits such as repetitive hand washing and hair trimming. Twelve patients (48.0\%) reported feeling 
apathetic or sad with persistence of mood symptoms despite treatment with antidepressants.

Among the 19 subjects with lv-FTD, word finding difficulty was a prominent symptom (89.5\%). Subjects often had difficulty expressing themselves and constructed increasingly hesitant, shorter, and ungrammatical sentences alongside reduced sentence comprehension. Eleven out of 17 PNFA subjects (64.7\%) had limb apraxia in contrast with 9 out of 25 patients (36.0\%) in the bv-FTD group, this higher incidence possibly reflecting PNFA as an inherent tauopathy.

\section{Cognitive Scores}

Three subjects in the bv-FTD group and 2 in the lv-FTD group could not undergo neuropsychological evaluation due to severe behavioral changes and mutism, respectively. The mean MMSE score was 16.1 for bv-FTD and 16.2 for lv-FTD subjects. The corresponding FAB scores were 11.3 and 9.8, respectively. On the MOCA, bv-FTD subjects had a mean score of 15.9 and lv-FTD subjects had a mean score of 16.8 .

\section{Neuroimaging}

Thirty-eight FTD patients underwent MRI scans, with the remaining 6 receiving CT scans. All 38 patients with MRI demonstrated a varying degree of FLA, and 35 patients also demonstrated concomitant MTA. The mean total FLA score was 3.51 (the maximum score is 6), and the mean bilateral MTA score was 2.09 (the maximum score is 8) across all FTD subjects. Both bv-FTD and lv-FTD subjects had comparable FLA and MTA scores. None of the subjects had significant white matter changes (mean Fazekas score 0.44 out of a maximum of 3).

Nine patients had (FDG)-PET scans which demonstrated frontotemporal hypometabolism. A further 2 lv-FTD subjects underwent MRI SPECT scans, which demonstrated reduced perfusion in the left frontal and left temporal lobes.

\section{Longitudinal Follow-Up and Prognosis}

During the longitudinal follow-up, a significant percentage of patients developed mixed behavioral and language symptoms (fig. 1). Among the bv-FTD subjects, 15 (60.0\%) went on to develop features of PNFA or SD, and 7 (28.0\%) eventually became mute. Among the PNFA subjects, 7 (36.8\%) went on to develop behavioral changes similar to bv-FTD, and $2(10.5 \%)$ developed late-stage mutism. The 2 SD patients in the study remained pure SD subtypes.

\section{Discussion}

The demographic and clinical profiles of FTD patients in Southeast Asia are consistent with the existing literature. Similar to North Asian and Western studies, bv-FTD is the predominant type of FTD among Southeast Asians (table 3). The female predominance among our FTD patients is comparable to the report from Japan, but far higher compared to reports from China and other Western countries [16-20]. The age of onset of FTD among Southeast Asians is consistent with reports from China and Western countries. The mean MMSE score at presentation is comparable to that in the Japanese study but lower than that in the Western studies. This observation may reflect the late presentation to medical attention related to lower awareness of FTD symptoms and lower literacy rates in Southeast Asia.

In our study, $60 \%$ of bv-FTD patients developed an lv-FTD syndrome within 8 years of presentation, and $36.8 \%$ of lv-FTD patients developed a bv-FTD syndrome within the same time frame. In a previous report by Kertesz et al. [6], 68.7\% of their bv-FTD patients devel- 


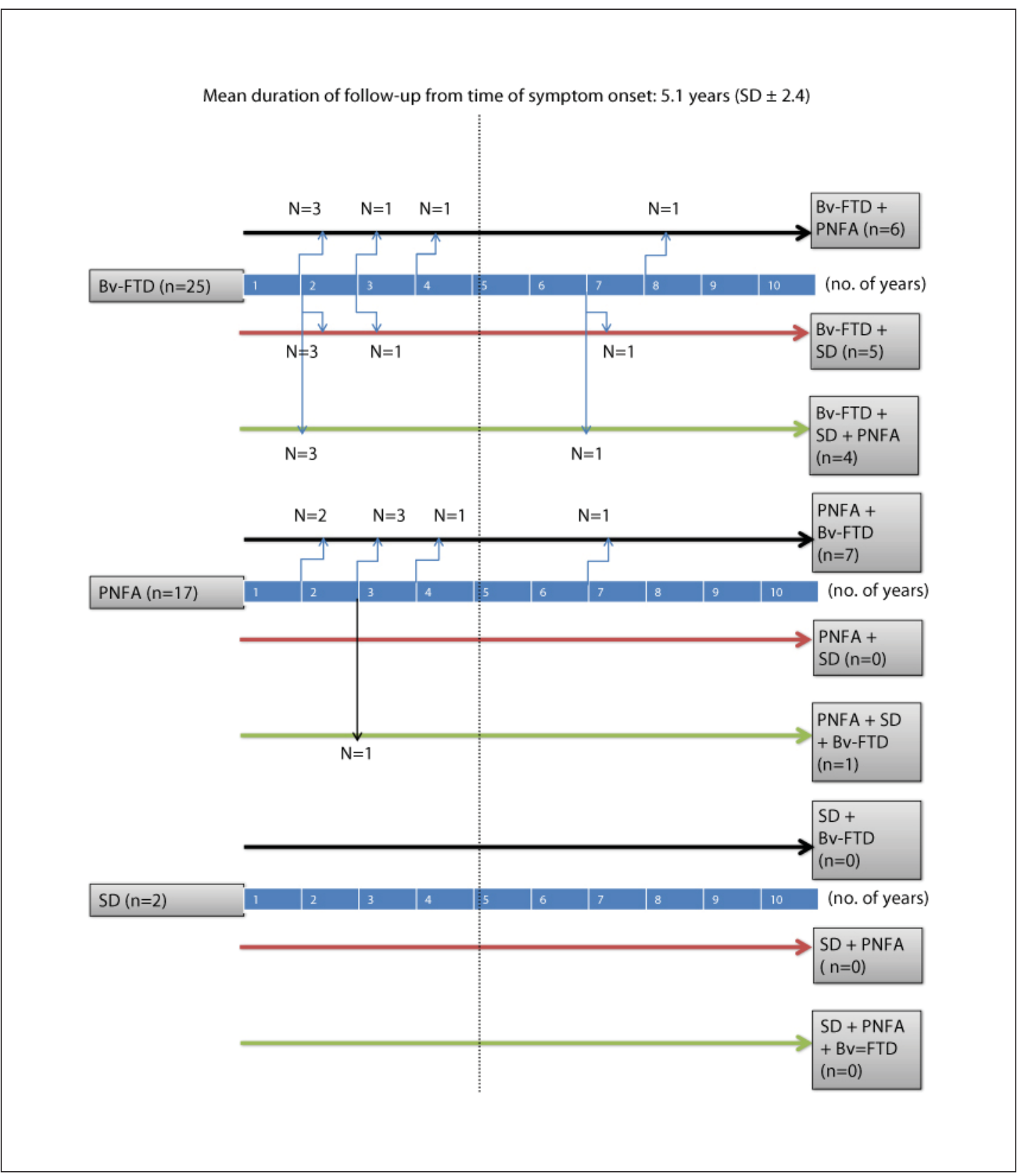

Fig. 1. Longitudinal follow-up of FTD subtypes.

oped lv-FTD and $31.8 \%$ of their lv-FTD patients developed bv-FTD as a second syndrome. The findings from both studies are highly consistent suggesting that about $2 / 3$ of FTD patients who initially present with frontal behavioral changes will go on to develop language deficits. Similarly, about 1/3 of both Asian and Western lv-FTD patients will go on to develop frontal behavioral changes during the course of their disease.

Memory dysfunction was a significant finding in the majority of our FTD subjects and deserves special mention. It was a reported symptom in 24 out of 44 (54.5\%) FTD referrals, alongside behavioral changes and language difficulties. On detailed history taking, memory dysfunction was present in 39 out of 44 (88.6\%) FTD subjects. Although never the core symp- 

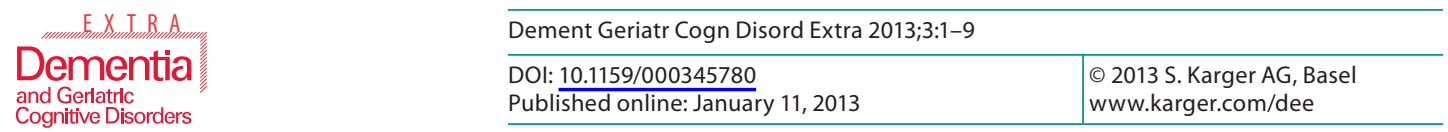

Tan et al.: Frontotemporal Dementia in Southeast Asia: A Comparative Study

Table 3. FTD profile across different countries

\begin{tabular}{|c|c|c|c|c|c|c|}
\hline & $\begin{array}{l}\text { Singapore: } \\
\text { current } \\
\text { study }\end{array}$ & $\begin{array}{l}\text { Japan: } \\
\text { Hokoishi } \\
\text { et al., 2001 [16] }\end{array}$ & $\begin{array}{l}\text { China: } \\
\text { Ren et al., } \\
2012 \text { [17] }\end{array}$ & $\begin{array}{l}\text { Australia and UK: } \\
\text { Piguet et al., } \\
2011 \text { [18] }\end{array}$ & $\begin{array}{l}\text { USA: } \\
\text { Johnson et al., } \\
2005 \text { [19] }\end{array}$ & $\begin{array}{l}\text { Greece: } \\
\text { Ioannidis et al., } \\
2012 \text { [20] }\end{array}$ \\
\hline bv-FTD & 25 & 16 & 35 & 13 & 200 & 111 \\
\hline lv-FTD & 19 & 8 & 14 & 8 & 153 & 83 \\
\hline Male, \% & 31.8 & 37.5 & 51.0 & 52.4 & 56.4 & 50 \\
\hline Mean age at onset (range), years & $56(33-71)$ & $68(51.4-83.4)$ & 58 & $60(42-70)$ & $59.9(35-80)$ & $65(40-79)$ \\
\hline Mean duration of symptom-to-diagnosis, years & 2.7 & 3.4 & NA & 9.1 & NA & 2.9 \\
\hline Mean MMSE score & 16.2 & 16.6 & 14.7 & NA & 22.2 & NA \\
\hline Mean duration of education, years & 10.8 & NA & NA & NA & 14.8 & NA \\
\hline Family history of dementia, $\%$ & 13.6 & None & $\begin{array}{l}\text { bv-FTD 20, } \\
\text { lv-FTD } 0\end{array}$ & None & NA & 4.3 \\
\hline
\end{tabular}

tom, FTD subjects were often reported to misplace items, forget names, or engage in repetitive questioning as a result of memory disturbance. A relative sparing of episodic memory in FTD has always been part of the differentiating core feature from AD and forms part of its diagnostic criteria. However, studies have shown that some patients with otherwise typical FTD can be amnestic from presentation, or even develop memory deficits in bv-FTD similar to early AD [21, 22]. A recent review by Hornberger and Piguet [23] argued for a reevaluation of the importance of memory disturbance in the clinical diagnosis of FTD, in light of supportive evidence pointing towards impairment of episodic memory, especially in bv-FTD. Indeed, we support the notion that overreliance on the absence of memory complaints as an inclusion criteria for the diagnosis of FTD may lead to an underdiagnosis of this condition. Among the behavioral symptoms, disturbance in social awareness, disinhibited behavior, and apathy predominate [24].

A combination of a global cognitive screening tool such as the MMSE, combined with a test of executive function such as the FAB, is useful in the screening for FTD. Eighty-one percent of our FTD patients had a MMSE score of $<24$, and $97.7 \%$ had combined scores below normal values when both MMSE and FAB (score $<12)$ tests were applied.

The portrayal of FTD as a clinically heterogeneous dementia syndrome is emphasized by our study, with 22 (50\%) subjects developing significant bv- and lv-FTD symptom overlap during the course of their disease. The overlap in symptomatology between bv-FTD and lvFTD was previously described by Snowden et al. [25].

Across the board, FTD remains a disease which is diagnosed late, with duration of symptom-to-diagnosis ranging from 2.7 to 9.1 years. By the time of diagnosis, most patients have cognitive scores in the dementia range. Clearly, there is an urgent need not only in developing treatment-related strategies of FTD, but also in early diagnosis through public awareness and new biomarkers.

\section{Disclosure Statement}

This study is not industry sponsored. Y.-L.T. and A.N. report no disclosures. N.K. has received CME sponsorship from Lundbeck, Novartis and Eisai. He has also received research funding from Singhealth Foundation, Media Development Authority of Singapore and the National Medical Research Council of Singapore. 


\section{References}

-1 Ratnavalli E, Brayne C, Dawson K, Hodges JR: The prevalence of frontotemporal dementia. Neurology 2002;58:1615-1621.

-2 The Lund and Manchester Groups: Clinical and neuropathological criteria for frontotemporal dementia. J Neurol Neurosurg Psychiatry 1994;57:416-418.

- 3 Pijnenburg YA, Mulder JL, van Swieten JC, Uitdehaag BM, Stevens M, Scheltens P, Jonker C: Diagnostic accuracy of consensus diagnostic criteria for frontotemporal dementia in a memory clinic population. Dement Geriatr Cogn Disord 2008;25:157-164.

-4 Rascovsky K, Hodges JR, Knopman D, Mendez MF, Kramer JH, Neuhaus J, van Swieten JC, Seelaar H, Dopper EG, Onyike CU, Hillis AE, Josephs KA, Boeve BF, Kertesz A, Seeley WW, Rankin KP, Johnson JK, Gorno-Tempini ML, Rosen H, Prioleau-Latham CE, Lee A, Kipps CM, Lillo P, Piguet O, Rohrer JD, Rossor MN, Warren JD, Fox NC, Galasko D, Salmon DP, Black SE, Mesulam M, Weintraub S, Dickerson BC, Diehl-Schmid J, Pasquier F, Deramecourt V, Lebert F, Pijnenburg Y, Chow TW, Manes F, Grafman J, Cappa SF, Freedman M, Grossman M, Miller BL: Sensitivity of revised diagnostic criteria for the behavioural variant of frontotemporal dementia. Brain 2011;134:2456-2477.

5 Gorno-Tempini ML, Hillis AE, Weintraub S: Classification of primary progressive aphasia and its variants. Neurology 2011;76:1006-1014.

-6 Kertesz A, Mcmonagle P, Blair M, Davidson W, Munoz DG: The evolution and pathology of frontotemporal dementia. Brain 2005;128:1996-2005.

-7 Kertesz A, Munoz D: Relationship between frontotemporal dementia and corticobasal degeneration/ progressive supranuclear palsy. Dement Geriatr Cogn Disord 2004;17:282-286.

-8 Folstein MF, Folstein SE, McHugh PR: 'Mini-Mental State'. A practical method for grading the cognitive state of patients for the clinician. J Psychiatr Res 1975;12:189-198.

-9 Nasreddine ZS, Phillips NA, Bédirian V, Charbonneau S, Whitehead V, Collin I, Cummings JL, Chertkow H: The Montreal Cognitive Assessment, MoCA: a brief screening tool for mild cognitive impairment. J Am Geriatr Soc 2005;53:695-699.

-10 Dubois B, Slachevsky A, Litvan I, Pillon B: The FAB: a Frontal Assessment Battery at bedside. Neurology 2000;55:1621-1626.

-11 Chong MS, Lim WS, Chan SP, Feng L, Niti M, Yap P, Yeo D, Ng TP: Diagnostic performance of the Chinese Frontal Assessment Battery in early cognitive impairment in an Asian population. Dement Geriatr Cogn Disord 2010;30:525-532.

-12 Dong Y, Lee WY, Basri NA, Collinson SL, Merchant RA, Venketasubramanian N, Chen CL: The Montreal Cognitive Assessment is superior to the Mini-Mental State Examination in detecting patients at higher risk of dementia. Int Psychogeriatr 2012;24:1749-1755.

-13 Pasquier F, Leys D, Weerts JG, Mounier-Vehier F, Barkhof F, Scheltens P: Inter- and intra-observer reproducibility of cerebral atrophy assessment on MRI scans with hemispheric infarcts. Eur Neurol 1996;36:268-272.

-14 Scheltens P, Leys D, Barkhof F, Huglo D, Weinstein HC, Vermersch P, Kuiper M, Steinling M, Wolters EC, Valk J: Atrophy of medial temporal lobes on MRI in 'probable' Alzheimer's disease and normal ageing: diagnostic value and neuropsychological correlates. J Neurol Neurosurg Psychiatry 1992; 55:967-972.

-15 Fazekas F, Chawluk JB, Alavi A, Hurtig HI, Zimmerman RA: MR signal abnormalities at $1.5 \mathrm{~T}$ in Alzheimer's dementia and normal aging. AJR Am J Roentgenol 1987;149:351-356.

- 16 Hokoishi K, Ikeda M, Maki N, Nebu A, Shigenobu K, Fukuhara R, Komori K, Tanabe H: Frontotemporal lobar degeneration: a study in Japan. Dement Geriatr Cogn Disord 2001;12:393-399.

-17 Ren RJ, Huang Y, Xu G, Li CB, Cheng Q, Chen SD, Wang G: History, present, and progress of frontotemporal dementia in China: a systematic review. Int J Alzheimers Dis 2012;2012:587215.

- 18 Piguet O, Halliday GM, Reid WG, Casey B, Carman R, Huang Y, Xuereb JH, Hodges JR, Kril JJ: Clinical phenotypes in autopsy-confirmed Pick disease. Neurology 2011;76:253-259.

-19 Johnson JK, Diehl J, Mendez MF, Neuhaus J, Shapira JS, Forman M, Chute DJ, Roberson ED, PaceSavitsky C, Neumann M, Chow TW, Rosen HJ, Forstl H, Kurz A, Miller BL: Frontotemporal lobar degeneration: demographic characteristics of 353 patients. Arch Neurol 2005;62:925-930.

-20 Ioannidis P, Konstantinopoulou E, Maiovis P, Karacostas D: The frontotemporal dementias in a tertiary referral center: classification and demographic characteristics in a series of 232 cases. J Neurol Sci 2012;318:171-173. 
Tan et al.: Frontotemporal Dementia in Southeast Asia: A Comparative Study

21 Graham AJ, Davies R, Xuereb J: Pathologically proven frontotemporal dementia presenting with severe amnesia. Brain 2005;128:597-605.

-22 Hornberger M, Piguet O, Graham AJ: How preserved is episodic memory in behavioural variant frontotemporal dementia? Neurology 2010;74:472-479.

-23 Hornberger M, Piguet O: Episodic memory in frontotemporal dementia: a critical review. Brain 2012; 135:678-692.

-24 Diehl-Schmid J, Pohl C, Perneczky R, Förstl H, Kurz A: Behavioral disturbances in the course of frontotemporal dementia. Dement Geriatr Cogn Disord 2006;22:352-357.

25 Snowden JS, Neary D, Mann DM: Fronto-Temporal Lobar Degeneration: Fronto-Temporal Dementia, Progressive Aphasia, Semantic Dementia. Edinburgh, Churchill Livingstone, 1996. 